\title{
BMI open Strategies TO reduce time delays in patients with AcuTe coronary heart disease treated with primary PCI - the STOP WATCH study: a multistage action research project
}

To cite: Tödt T, Thylén I, Alfredsson J, et al. Strategies TO reduce time delays in patients with AcuTe coronary heart disease treated with primary $\mathrm{PCl}-$ the STOP WATCH study: a multistage action research project. BMJ Open 2013;3 e003493. doi:10.1136/ bmjopen-2013-003493

- Prepublication history and additional material for this paper is available online. To view these files please visit the journal online (http://dx.doi.org/10.1136/ bmjopen-2013-003493).

Received 26 June 2013 Revised 17 July 2013 Accepted 19 July 2013

\footnotetext{
${ }^{1}$ Division of Cardiovascular Medicine, Department of Medical and Health Sciences, Faculty of Health Sciences, Linköping University ${ }^{2}$ Department of Cardiology, County Council of Östergötland, Linköping, Sweden
}

Correspondence to

Dr Tim Tödt:

tim.todt@lio.se

Tim Tödt, ${ }^{1,2}$ Ingela Thylén,, ${ }^{1,2}$ Joakim Alfredsson,,
Magnus Janzon ${ }^{1,2}$

\section{ABSTRACT}

Objective: To identify, evaluate and reduce system delay times in an ST-elevation myocardial infarction (STEMI) network by targeted reorganisation of logistics and personal feedback to staff on time delays.

Design: Multistage action research project. Three study phases were used (exploration, tailored intervention and evaluation).

Setting: Single centre study, Sweden.

Patients: Consecutive patients $(\mathrm{N}=156)$ with prehospital STEMI onset treated with primary percutaneous coronary intervention (PCI).

Interventions: Areas of delays were identified through participant observations and collaborative discussions. To increase the awareness of delay factors, continuous feedback on time delays was given. Elements of the logistics' reorganisation were (1) prioritised ECG recording by emergency medical services personnel, (2) central evaluation of ECG in all patients and (3) start of $\mathrm{PCl}$ procedure when two of three $\mathrm{PCl}$ team members were on site. Multiple key time measurements were made before $(\mathrm{N}=67)$ and after $(\mathrm{N}=89)$ the intervention.

Main outcomes: Time difference (minutes) in system delay between the preintervention and postintervention phases.

Results: Time from first medical contact (FMC) to a patent artery and time from FMC-to-catheter laboratory (cath-lab) arrival decreased by 6 and $12 \mathrm{~min}$, respectively (ns). Time from FMC-to-ECG recording remained unchanged after the intervention. Time from ECG to decision for primary $\mathrm{PCl}$ was reduced by 6 min, $p=0.004$ and time from ECG-to-cath-lab arrival by $11 \mathrm{~min}, \mathrm{p}=0.02$. Total time from diagnosis to a patent artery decreased by $11 \mathrm{~min}$ (ns).

Conclusions: Identification of time delays in an STEMI network with awareness of delay factors, reorganisation of logistics and continuous feedback can reduce system delay times significantly.

\section{ARTICLE SUMMARY}

Article focus

- In patients with ST-elevation myocardial infarction (STEMI), rapid reperfusion therapy when every minute counts is a key factor for successful treatment and outcome but continues to be administered too late.

- We hypothesised that (1) a detailed identification of system time delays, followed by (2) personal feedback on time delays to staff involved in the acute care of STEMI patients and (3) targeted reorganisation of logistics, would (4) lead to a reduction in system time delays in an STEMI network characterised by a high frequency of direct admission by ambulance to the catheter laboratory.

- The aim was to identify, evaluate and improve system time delays in an STEMI network using an action research approach.

Key messages

- Identification of system time delays, collaborative discussions and feedback to staff involved in STEMI care resulted in three tailored reorganisations: (1) emergency medical services personnel prioritising ECG recording, (2) central evaluation of ECG in all patients with suspected STEMI and (3) starting percutaneous coronary intervention $(\mathrm{PCl})$ procedure with two of three $\mathrm{PCl}$ team members on site.

- Multiple key time measurements before and after the intervention showed that the total time from diagnosis to a patent artery decreased from 95 to $84 \mathrm{~min}$. Though not statistically significant, it is an important reduction when it happens to reach a successful outcome for STEMI patients.

- Action research can be used as an effective tool to identify time delays in an STEMI network and contribute to awareness of delay factors and facilitate reorganisation of logistics. Together with continuous feedback on time delays that stimulate reflective clinical behaviour, system delay times can be reduced substantially. 


\section{ARTICLE SUMMARY}

Strengths and limitations of this study

- The study's multistage action research approach allowed interpersonal involvement and awareness and a detailed exploration-as well as improvement-of system time delays, not possible when focusing on reorganisation of logistics only.

- This was a single centre study including a relatively small number of patients for the multiple time point measurements. Involvement and interventions at the emergency room could have been more focused. Multiple interventions make it difficult to draw firm conclusions about which single intervention had the largest effect on reduction of the delay time.

\section{INTRODUCTION}

In patients with ST-elevation myocardial infarction (STEMI), shorter time from the time from first medical contact (FMC) to a patent artery has been associated with lower mortality ${ }^{1}$ and lower risk for re-admissions due to heart failure. ${ }^{2}$ Though rapid coronary reperfusion reduces mortality in patients with STEMI, reperfusion therapy continues to be administered too late. ${ }^{3}$ Hospitals that have short door-to-balloon time have adopted strategies such as prehospital ECGs to activate the catheter laboratory (cath-lab), an attending cardiologist always on site, explicit goals, continuous feedback on time delays and an interdisciplinary collaboration throughout the process. ${ }^{4}$ Ward et $a l^{5}$ identified periods during the sequence of events where time delays were unacceptable (mainly ECG to exit emergency room (ER) and sheath to balloon inflation) and they made changes in their local guidelines for STEMI that reduced door-to-balloon times from 136 to $82 \mathrm{~min}$. Other investigators have been able to achieve similar improvements simply by monitoring performance on door-to-balloon times without changing the STEMI strategy. ${ }^{6}$ These two studies identified the time delays retrospectively and studied patients arriving at the ER at the Percutaneous Coronary Intervention (PCI) Centre. The aim of the present study was to identify and evaluate system delay times in an STEMI network using action research. We hypothesised that identification of time delays, followed by targeted reorganisation of logistics and personal feedback on time delays to staff involved in the care of STEMI patients, would lead to a reduction in system delay time in an STEMI network characterised by a high frequency of direct admission by ambulance to the cath-lab.

\section{METHODS \\ Setting}

In the county of Östergötland with a population of 430000 people, there are three hospitals. The Heart Centre at the University Hospital of Linköping, the only one with cath-lab facilities, is located in the centre of the county with a distance to the two referring hospitals of $45 \mathrm{~km}$ and with a distance to the outmost border of the county of $100 \mathrm{~km}$. The average transportation time for STEMI patients admitted by the Emergency Medical Services (EMS) in the county is $30 \mathrm{~min}$, with approximately $70 \%$ arriving in ambulances all staffed with nurses. Communication with the Heart Centre is by phone as well as through an on-board on-line computer system. Since 2005, the Heart Centre has adopted a strategy of providing primary PCI for all patients with STEMI in the county. Patients who present with symptoms of acute coronary syndrome and have an ECG recorded by the EMS that shows ST-elevation and extensive anterior ST-depression indicative of posterior STEMI or Bundle Branch Block are sent directly to the cath-lab with the intention of employing primary PCI. In case the patient is admitted to the ER, the emergency physician contacts the cardiologist on call at the Heart Centre when STEMI is suspected.

\section{Study design}

The study was carried out between 2006 and 2011 and designed as a multistage action research project. Three study phases were used: exploration (preintervention phase), tailored intervention and evaluation (postintervention phase). The study involved: (1) collaborative discussions and participant observations to identify system delay, (2) multiple time point measurements before the intervention, (3) awareness of the delay factors, (4) reorganisation of logistics and (5) multiple time point measurements after the intervention (figure 1).

\section{Action research}

Action research is characterised by participation and begins with recognition of social and institutional problems and need for change, ${ }^{7}$ focusing on a concern for doing research with, for and by people, rather than on

Figure 1 Timeline for the study. 
them. There is collaboration between researchers and study participants in the process of defining the problem, ${ }^{8}$ the selection of an approach and research methods, the analysis of the data and the use to which the findings are to be put. The aim is to produce not only knowledge but also action, as well as to develop processes of collaboration and dialogue and to raise awareness of a joint problem. Action research is an iterative process in which researchers and practitioners act together in the context of an identified problem to discover and effect positive change within a mutually acceptable ethical framework ${ }^{9}$ (box 1 ).

\section{Preintervention phase}

The preintervention phase was carried out between 25 November 2006 and 14 March 2007 and began with identification and measurement of multiple time points for a total of 67 consecutive patients with STEMI admitted for primary PCI at the Heart Centre (box 2). To be included in the study, patients had to have: (1) symptom onset outside hospital, (2) ST-elevation or extensive ST-depression indicative of posterior infarction or bundle branch block on the ECG, (3) a final diagnosis of myocardial infarction (I21 to I23, ICD 10), (4) treatment with primary PCI at the Heart Centre and (5) living in the catchment area of the Heart Centre. Patient delay was defined as the time from symptom onset to FMC. FMC was defined as the time when the patient called the EMS for those patients admitted directly to the cath-lab and for other patients it was the time when the patient arrived at the ER. Time to decision was defined as the time from ECG recording to the time when the cardiologist on call decided on primary PCI. Cath-lab time was time from arrival at the cath-lab to balloon inflation, activation of the thrombectomy device or thrombolysis in myocardial infarction (TIMI) 2-3 flow in the infarct-related artery (IRA), whichever came first. System delay time was defined as the time from FMC to balloon inflation/thrombectomy or visualisation of TIMI 2-3 flow in the IRA, whichever was achieved first (figure 2).

\section{Box 1 What are the key features of action research?}

- The key features of action research include its collaborative nature, its democratic approach to power and education in the research process, and its emphasis on taking action on an issue. The extensive collaboration between researchers and study participants (eg, staff) in action research must extend across each stage of research, from identifying the problem to disseminating the results. This collaboration entails shared control of the agenda and also involves reciprocal education to improve researchers' and research participants' understanding of one another's positions and contributions. Finally, the study must blend scientific inquiry with social action by creating knowledge that is relevant to the research participants' needs and interests.

\section{Box 2 Multiple time point measurements}

- Symptom awareness

- Contact with the emergency medical services

- Arrival of ambulance at the patient's location

- Transmission of ECG to the Coronary Care Unit (CCU) at the Heart Centre

- Start of transfer of patient to the Heart Centre

- Time of contact with cardiologist on call at the Heart Centre

- Decision to perform percutaneous coronary intervention (PCI)

- Contact with PCI team

- Arrival of the patient at ambulance entrance at the Heart Centre

- Arrival of the patient at the CCU and/or PCI unit

- Administration of local anaesthesia as a marker for start of PCI

- Balloon inflation or activation of a thrombectomy device, whichever occurs first

- Time of thrombolysis in myocardial infarction 2-3 flow in the infarct-related artery

- Last performed angiogram as a marker for end of $\mathrm{PCl}$

Among patients arriving at the emergency room, additional
time points measured were
Arrival of the patient at the emergency room
Recording of an ECG
Detection of ST-segment elevation myocardial infarction
Decision to transfer patient for primary PCI
Arrival of ambulance at the referring hospital with no cath-lab
on site

There was extensive collaboration between researchers and staff at the Heart Centre and the EMS in order to identify areas of time delay that we believed could be influenced through targeted reorganisation of logistics. These areas were identified through collaborative analysis of the measured delay times and through participant observations at the EMS, the coronary care unit (CCU) and the cath-lab at the Heart Centre. Furthermore, several discussions with interventionists, nurses, representatives from the EMS, staff at the ER and leading physicians, including those at the spoke hospitals participating in the treatment of STEMI patients, were carried out. Discussions and participant observations revealed first and foremost that recording and transmitting an ECG was not the first thing carried out when approaching a patient with suspected STEMI. Moreover, in the preintervention phase, ECG recordings from ambulances in the catchment area of the three hospitals in the county of Östergötland were transmitted and analysed at the CCU at the respective hospital. Finally, the PCI team (one interventionist and two nurses) did not start the procedure until all three members of the PCI team were in place at the cath-lab.

\section{Tailored interventions}

The interventions were carried out between 2008 and 2010 and involved interpersonal interventions with 


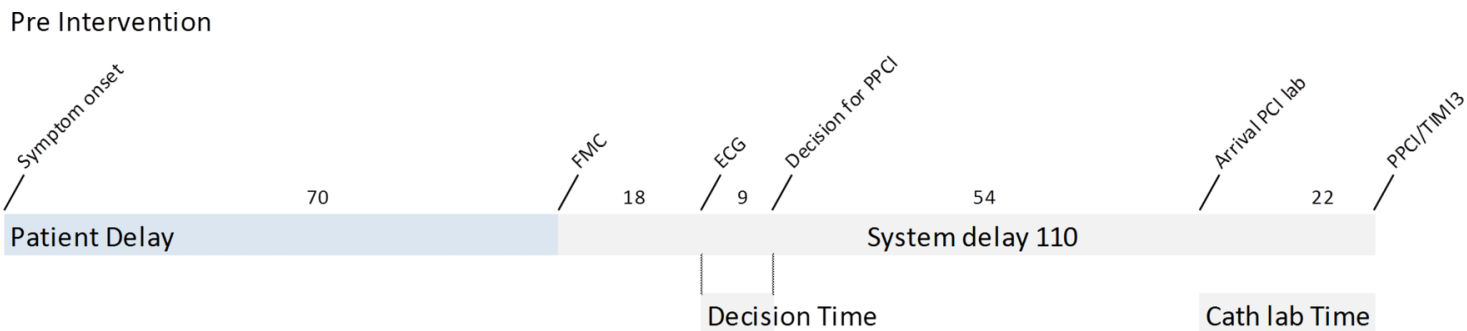

84

Time from FMC to Cath Lab

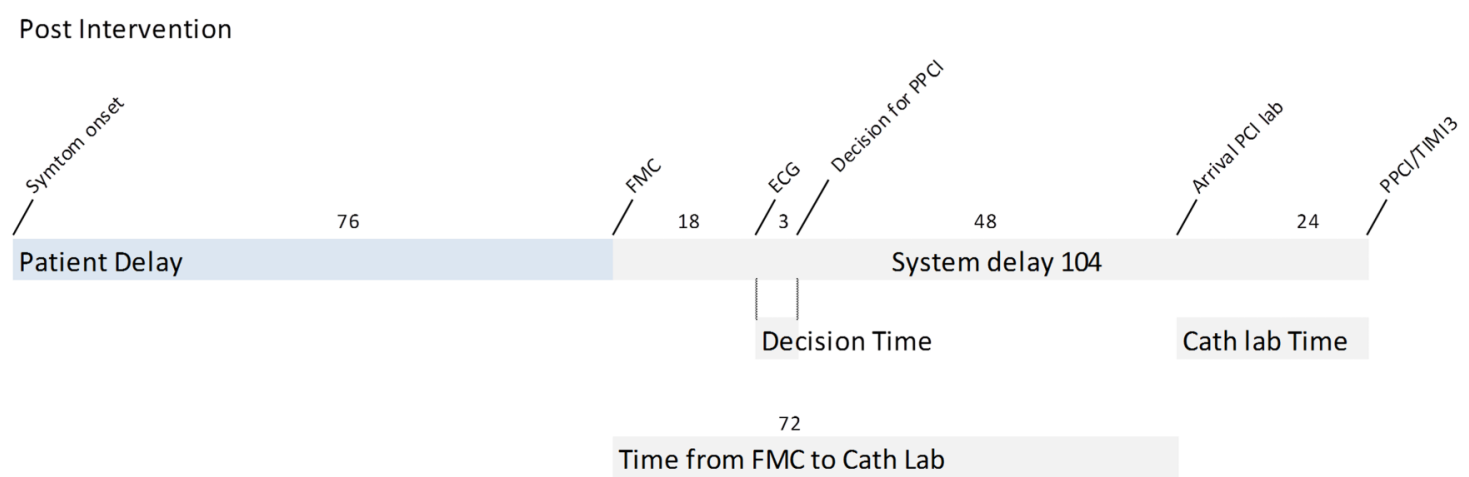

Figure 2 Delays from symptom onset to primary percutaneous coronary intervention in patients with ST-segment elevation myocardial infarction. Numbers indicate median time (minutes). FMC, First Medical Contact; PPCl, primary percutaneous coronary intervention; TIMI3, thrombolysis in myocardial infarction grade 3 coronary flow, that is, normal flow.

awareness of the delay factor, and system interventions with reorganisation of logistics. In addition to the targeted interventions and outside the study, the board of the Heart Centre decided to have an attending cardiologist on site $24 \mathrm{~h} / 7$ days a week from 14 January 2007 (figure 1).

\section{Awareness of the delay factor}

Staff members involved in the treatment of STEMI patients were continuously reminded of the delay factors in the outcome of STEMI. The 'time is muscle' principle was highlighted at meetings and clinical discussions involving the STEMI population. In addition, personal written feedback on time delays for every STEMI patient (de-identified) was sent to physicians and EMS personnel involved in the treatment. Individuals were encouraged to contact the principal investigator of the study to further discuss the delay times (see online supplementary appendix 1).

\section{Reorganisation of logistics}

The following areas of targeted refining of logistics were carried out: (1) EMS personnel were instructed to prioritise ECG recording, (2) evaluation of the ECG in all patients with suspected STEMI in the county of Östergötland was made centrally at the CCU at the Heart Centre and (3) the PCI team was to start the PCI procedure as soon as two of the three members were on site.

\section{Postintervention phase}

After refining the logistics and training personnel in the new procedures, the records for another 89 consecutive patients with STEMI (postintervention group) treated between 1 October 2010 and 17 February 2011 were reviewed for time delays in a manner similar to that used for the preintervention group.

\section{Statistical analysis}

Data were analysed with SPSS software, V.20.0 (SPSS, Chicago, Illinois, USA). Continuous variables were reported as mean $\pm \mathrm{SD}$ or median (25th-75th centile) as appropriate. For normally distributed variables, the twotailed Student $\mathrm{t}$ test and for non-normally distributed variables the Mann-Whitney $U$ test was used to verify statistical differences between the preintervention and postintervention groups. Categorical variables were expressed as counts (percentage). Statistical significance was assessed with the $\chi^{2}$ or Fisher's exact tests.

\section{RESULTS}

The mean age of patients in the study was 67 years and one-third of the patients were women. There were no significant differences in baseline characteristics 
Table 1 Baseline characteristics

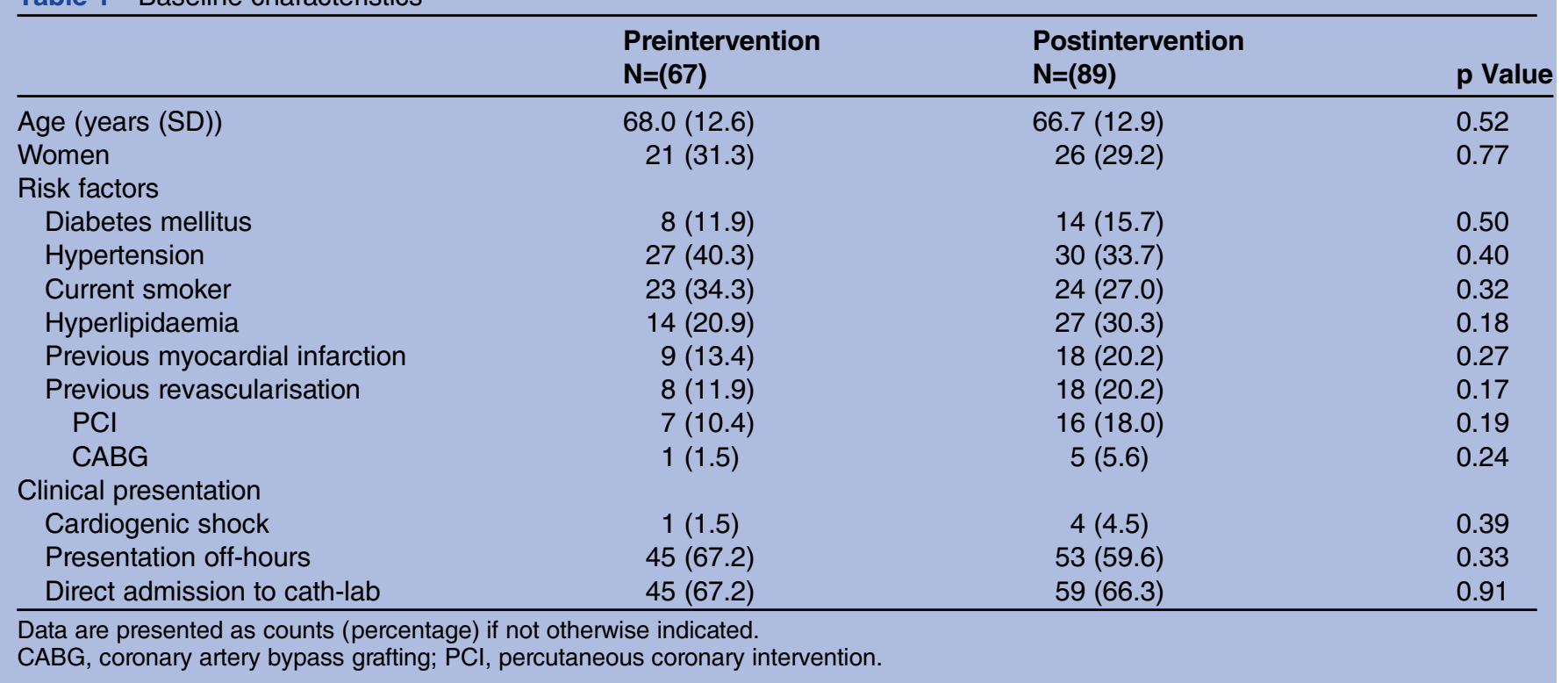

between the preintervention and postintervention groups (table 1). Sixty-seven per cent of patients were admitted directly to the cath-lab by the EMS system. The patient delay remained unchanged during the preintervention and postintervention phases (table 2). Important delay times for patients admitted directly to the cath-lab are given separately in the lower half of table 2.

The system delay time decreased from 110 to $104 \mathrm{~min}$, and time from FMC to cath-lab arrival from 84 to 72 min; however, these changes did not reach statistical significance. The time from FMC to ECG recording remained unchanged after the intervention, 18 min both before and after. There was a $3 \mathrm{~min}$ reduction in time from ambulance arrival at the scene to departure to the Heart Centre, but this too was not statistically significant. The time delay from ECG recording to decision for primary PCI was reduced from 9 to $3 \mathrm{~min}, \mathrm{p}=0.004$, which was also reflected in the $11 \mathrm{~min}$ shorter time to arrival in the cath-lab after diagnosis of STEMI, $\mathrm{p}=0.02$. On the other hand, after changing the procedure so that only two of three members had to be on site to start

Table 2 Time delays

\begin{tabular}{|c|c|c|c|}
\hline & Preintervention $\mathrm{N}=(67)$ & Postintervention $\mathrm{N}=(\mathbf{8 9})$ & p Value \\
\hline \multicolumn{4}{|l|}{ Time delays, median, min (IQR) } \\
\hline Symptom to FMC & $70(32-173)$ & $76(34-154)$ & 0.77 \\
\hline FMC to ECG & $18(10-28)$ & $18(11-30)$ & 0.85 \\
\hline Ambulance arrival to departure from patient & $20(12-30)$ & $17(13-22)$ & 0.18 \\
\hline FMC to cath-lab & $84(68-115)$ & $72(62-102)$ & 0.07 \\
\hline FMC to balloon & $112(98-148)$ & $108(91-150)$ & 0.41 \\
\hline FMC to balloon or TIMI $2-3$ & $110(95-141)$ & $104(86-138)$ & 0.30 \\
\hline $\mathrm{ECG}$ to decision for primary $\mathrm{PCl}$ & $9(2-16)$ & $3(1-8)$ & 0.004 \\
\hline ECG to cath-lab & $66(53-85)$ & $55(43-70)$ & 0.02 \\
\hline ECG to balloon & $96(82-118)$ & $90(76-116)$ & 0.28 \\
\hline ECG to balloon or TIMI 2-3 & $95(76-114)$ & $84(68-110)$ & 0.19 \\
\hline Arrival at cath-lab to balloon & $28(22-35)$ & $32(24-42)$ & 0.03 \\
\hline Arrival at cath-lab to balloon or TIMI 2-3 & $22(17-30)$ & $24(19-34)$ & 0.06 \\
\hline Patients with direct admission to cath-lab & $\mathrm{N}=(45)$ & $\mathrm{N}=(59)$ & \\
\hline Symptom to FMC & $55(24-138)$ & $74(27-144)$ & 0.70 \\
\hline FMC to balloon or TIMI 2-3 & $104(83-130)$ & $102(86-129)$ & 0.82 \\
\hline FMC to ECG & $18(15-29)$ & $18(11-30)$ & 0.88 \\
\hline ECG to decision for primary $\mathrm{PCl}$ & $4(1-11)$ & $2(1-5)$ & 0.19 \\
\hline ECG to cath-lab & $56(43-68)$ & $53(42-64)$ & 0.30 \\
\hline Arrival at cath-lab to balloon or TIMI 2-3 & $25(13-35)$ & $24(19-31)$ & 0.86 \\
\hline
\end{tabular}


the PCI procedure, there was an increase in the cath-lab time in the postintervention phase from 22 to $24 \mathrm{~min}$ (ns; table 2). The total time from diagnosis to a patent artery, though not statistically significant, decreased from 95 to 84 min (table 2).

The proportion of patients receiving GIIb/IIIa inhibitors (in all cases abciximab) before arrival at the cath-lab was significantly higher in the preintervention phase, which was reflected in a more frequent identification of a patent artery at the first angiogram, $43 \%$ vs $29 \%$, ns. There were no differences in the IRA between the groups (table 3). A separate analysis comparing patients in the preintervention group before and after 14 January 2007 (ie, when the cardiologist on call was on site $24 / 7$ ) revealed a decrease in decision time from 13 to 6 min, ns.

During the preintervention phase, all patients were catheterised by the femoral route. In the postintervention phase, radial puncture became more and more the standard access site for primary PCI. Analysis of the puncture site irrespective of the inclusion period revealed preparation time (defined as the time from arrival at the cath-lab to infiltration of the access site with anaesthetics) and cath-lab time to be 10 and $23 \mathrm{~min}$ for the femoral route and 12 and $24 \mathrm{~min}$ for the radial route, respectively, ns. A separate comparison of patients with an occluded IRA and those with a patent IRA at the first angiogram irrespective of the time period revealed a shorter time from arrival at the cath-lab to balloon inflation for those with occluded IRA, 26 vs $32 \mathrm{~min}, \mathrm{p}=0.006$.

\section{DISCUSSION}

By co-operative discussions with personnel involved in the STEMI care process, we identified points of time delay occurring during the period when patients with STEMI were being cared for. Through the reorganisation of logistics and continuous feedback on time delays in our STEMI network with an already high frequency of direct admission by ambulance to the cath-lab, we were able to reduce the time from diagnosis of STEMI to arrival at the cath-lab by $11 \mathrm{~min}$. Even though a reduction of $11 \mathrm{~min}$ between diagnosis of STEMI and a patent artery might seem small, de Luca et $a l^{10}$ showed in their meta-analysis that each $30 \mathrm{~min}$ of delay was associated with a relative risk for 1-year mortality of 1.075 . The time from FMC to arrival at the cath-lab and from FMC to a patent artery was reduced by 12 and $6 \mathrm{~min}$, respectively; however, this reduction was not statistically significant. The indication of initial improvement was, at least partially, hampered by an increased cath-lab time. The time from arrival at the cath-lab to balloon inflation, activation of the thrombectomy device or demonstration of a patent IRA, whichever came first, increased from 22 to 24 min during the study period. The cath-lab team was ready to accept the patient and start PCI procedure with two of three members on site, which probably contributed to the reduced time from diagnosis to cath-lab arrival. On the other hand, this may have made the procedure less effective during the initiation of this procedure if only two rather than three had been present. The preferred access site during the postintervention phase was the right radial artery. Studies have shown a slightly longer preparation and door-to-balloon time for the radial approach as compared with the femoral approach. ${ }^{11}$ In our study, preparation-time and cath-lab delay time appeared to be 1-2 min longer for radial access than for femoral access.

\section{Strategies to reduce system delay time}

Most studies have focused on door-to-balloon times, ${ }^{12}$ but this approach fails to take into account other reasons for system delay. ${ }^{13}$ We focused on improvement of the more robust and objective system delay time,

\begin{tabular}{|c|c|c|c|}
\hline & $\begin{array}{l}\text { Preintervention } \\
\mathrm{N}=(67)\end{array}$ & $\begin{array}{l}\text { Postintervention } \\
\mathrm{N}=(\mathbf{8 9})\end{array}$ & p Value \\
\hline Radial puncture & $0(0)$ & $53(59.6)$ & 0.0005 \\
\hline $\begin{array}{l}\text { Abciximab before } \\
\text { cath-lab }\end{array}$ & $50(74.6)$ & 44 (49.4) & 0.001 \\
\hline \multicolumn{3}{|l|}{ Infarct-related artery } & 0.03 \\
\hline LAD & 29 (43.3) & $43(48.3)$ & 0.53 \\
\hline $\mathrm{Cx}$ & $9(13.4)$ & 11 (12.2) & 0.84 \\
\hline RCA & $28(41.8)$ & $33(37.1)$ & 0.55 \\
\hline Left main & $0(0)$ & $1(1.1)$ & 1.0 \\
\hline Vein graft & $0(0)$ & $1(1.1)$ & 1.0 \\
\hline \multicolumn{4}{|c|}{ TIMI flow at first angiogram } \\
\hline TIMI 0-1 & $38(56.7)$ & $63(70.8)$ & 0.07 \\
\hline TIMI 2-3 & 29 (43.3) & $26(29.2)$ & 0.07 \\
\hline
\end{tabular}


specifically the time to decision by the cardiologist on call and the time to arrival at the cath-lab. Several strategies that reduce system delay time were used in our study including central evaluation of the ECG ${ }^{14}$ and realtime data feedback. ${ }^{15}$ We noted that the regularly given feedback resulted in intense, collaborative discussions among caregivers. Reflection on the individual's actions is seen as necessary for continuing professional development, ${ }^{16}$ and studies have suggested that increasing reflection on medical problems could improve clinical competence. ${ }^{17}$ Most of the reduction in system delay time in our study was achieved by shortening the time to decision by $6 \mathrm{~min}$. The probable cause of this improvement was the central evaluation of ECG and having an attending cardiologist on site. Independent of our study, the board of the Heart Centre decided to have an attending cardiologist on site 24/7 from 14 January 2007 to the present. The impact of this strategy on system delay time has been questioned. ${ }^{18}$ Field triage by the EMS with prehospital ECG and activation of the cath-lab team and the bypassing of local hospitals by admitting STEMI patients directly to the cath-lab has a documented impact on reducing system delay time. ${ }^{19}$ This strategy, which is common in Scandinavia, ${ }^{20}$ was used in $67 \%$ of our patients. During the study period, there was a significant reduction in the use of GIIb/IIIa administration upstream, probably caused by the results of the FINESSE study. ${ }^{21}$ This was reflected in a trend to less frequent patent IRA at the first angiogram. The time between arrival at the cath-lab to balloon inflation was $6 \mathrm{~min}$ longer for patients with a patent rather than occluded IRA at the first angiogram. This could be interpreted as indicating that PCI operators do not rush the procedure once they identify a patent IRA.

\section{System delay time in perspective}

The cath-lab delay time, in line with other studies, ${ }^{1}$ was not reduced. However, shorter time delays in the cath-lab have been reported from centres with $>700$ primary PCI annually. ${ }^{22}$ The European Society of Cardiology states that primary PCI (wire passage) should be performed within $90 \mathrm{~min}$ after FMC in all cases except in patients presenting early with large area at risk where PCI should be performed within $60 \mathrm{~min} .{ }^{23}$ In patients admitted from the ambulance directly to the cath-lab irrespective of the time period, the time from EMS arrival at the scene to a patent artery was $91 \mathrm{~min}$ in our study. These delay times are almost identical to the time delays reported by Terkelsen $e t a l .^{24}$ Moreover, time delays observed in the present study seem to be similar to those reported in other studies. ${ }^{25-30}$ Future research and strategy implementation should probably focus on earlier diagnosis of STEMI and increasing public awareness of STEMI to reduce treatment delay time in STEMI. ${ }^{31}$

\section{Limitations of the study}

This was a single centre study including a small number of patients for the multiple time point measurements.
We cannot exclude the possibility that a larger study population would have shown a different result. Ideally, we would randomise the patients to different strategies, but this is not possible for obvious reasons. However, because the system delay factor embraces a tension between local solutions at the Department of Cardiology and transferable knowledge at the EMS and the ER, action research was considered suitable in order to make the results more generally applicable. Interventions at the ER could have been more focused since we retrospectively noticed that one-third of the STEMI patients included in the study arrived directly in the ER. Lastly, multiple interventions make it difficult to draw firm conclusions about which single intervention had the largest effect on reduction of the delay time.

\section{CONCLUSION}

Action research can be used as an effective tool to identify time delays in an STEMI network and contribute to awareness of delay factors and facilitate reorganisation of logistics. Together with continuous feedback on time delays that stimulate reflective clinical behaviour, several system delay times could be reduced significantly.

Contributors TT, JA, ES and MJ participated in the study design. IT had the knowledge in action research. TT acquired the data and did the statistical analyses. TT wrote the initial draft, and all authors critically revised the manuscript.

Funding This research received no specific grant from any funding agency in the public, commercial or not-for-profit sectors.

\section{Competing interests None.}

Ethics approval The study protocol was approved by the Regional Ethical Review Board in Linköping (DNR M107-07) and adhered to the Declaration of Helsinki.

Provenance and peer review Not commissioned; externally peer reviewed.

Data sharing statement No additional data are available.

Open Access This is an Open Access article distributed in accordance with the Creative Commons Attribution Non Commercial (CC BY-NC 3.0) license, which permits others to distribute, remix, adapt, build upon this work noncommercially, and license their derivative works on different terms, provided the original work is properly cited and the use is non-commercial. See: http:// creativecommons.org/licenses/by-nc/3.0/

\section{REFERENCES}

1. Terkelsen CJ, Sorensen JT, Maeng M, et al. System delay and mortality among patients with STEMI treated with primary percutaneous coronary intervention. JAMA 2010;304:763-71.

2. Terkelsen CJ, Jensen LO, Tilsted $\mathrm{HH}$, et al. Health care system delay and heart failure in patients with ST-segment elevation myocardial infarction treated with primary percutaneous coronary intervention: follow-up of population-based medical registry data. Ann Intern Med 2011;155:361-7.

3. Chakrabarti A, Krumholz HM, Wang Y, et al. Time-to-reperfusion in patients undergoing interhospital transfer for primary percutaneous coronary intervention in the U.S: an analysis of 2005 and 2006 data from the National Cardiovascular Data Registry. J Am Coll Cardiol 2008;51:2442-3.

4. Bradley EH, Curry LA, Webster TR, et al. Achieving rapid door-to-balloon times: how top hospitals improve complex clinical systems. Circulation 2006;113:1079-85.

5. Ward MR, Lo ST, Herity NA, et al. Effect of audit on door-to-inflation times in primary angioplasty/stenting for acute myocardial infarction. Am J Cardiol 2001;87:336-8, A9. 
6. Shry EA, Eckart RE, Winslow JB, et al. Effect of monitoring of physician performance on door-to-balloon time for primary angioplasty in acute myocardial infarction. Am J Cardiol 2003;91:867-9.

7. Meyer J. Qualitative research in health care. Using qualitative methods in health related action research. BMJ 2000;320:178-81.

8. Polit DB. Developing an approach for a qualitative study. In:nursing research. Generating and assessing evidence for nursing practice. Polit DF and Beck CT, eds. Lippincott Williams \& Wilkins, 2008: 219-47.

9. Lingard L, Albert M, Levinson W. Grounded theory, mixed methods, and action research. BMJ 2008;337:a567.

10. De Luca G, Suryapranata H, Ottervanger JP, et al. Time delay to treatment and mortality in primary angioplasty for acute myocardial infarction: every minute of delay counts. Circulation 2004;109:1223-5.

11. Pancholy S, Patel T, Sanghvi K, et al. Comparison of door-to-balloon times for primary $\mathrm{PCl}$ using transradial versus transfemoral approach. Catheter Cardiovasc Interv 2010;75:991-5.

12. Krumholz HM, Herrin J, Miller LE, et al. Improvements in door-toballoon time in the United States, 2005 to 2010. Circulation 2011;124:1038-45.

13. Terkelsen CJ, Lassen JF. Treatment delays in ST elevation myocardial infarction. BMJ 2008;336:401-2.

14. Terkelsen CJ, Norgaard BL, Lassen JF, et al. Telemedicine used for remote prehospital diagnosing in patients suspected of acute myocardial infarction. J Intern Med 2002;252:412-20.

15. Lai CL, Fan CM, Liao PC, et al. Impact of an audit program and other factors on door-to-balloon times in acute ST-elevation myocardial infarction patients destined for primary coronary intervention. Acad Emerg Med 2009;16:333-42.

16. Robertson K. Reflection in professional practice and education. Aust Fam Phys [Review] 2005;34:781-3.

17. Koole S, Dornan T, Aper L, et al. Does reflection have an effect upon case-solving abilities of undergraduate medical students? BMC Med Educ 2012;12:75.

18. Camp-Rogers T, Kurz MC, Brady WJ. Hospital-based strategies contributing to percutaneous coronary intervention time reduction in the patient with ST-segment elevation myocardial infarction: a review of the "system-of-care" approach. Am J Emerg Med 2012;30:491-8.

19. Camp-Rogers T, Dante S, Kontos MC, et al. The impact of prehospital activation of the cardiac catheterization team on time to treatment for patients presenting with ST-segment-elevation myocardial infarction. Am J Emerg Med 2011;29:1117-24.

20. Terkelsen $\mathrm{CJ}$, Jensen LO, Tilsted $\mathrm{HH}$, et al. Primary percutaneous coronary intervention as a national reperfusion strategy in patients with ST-segment elevation myocardial infarction. Circ Cardiovasc Interv 2011;4:570-6.
21. Ellis SG, Tendera M, De Belder MA, et al. Facilitated PCl in patients with ST-elevation myocardial infarction. $N$ Engl J Med 2008;358:2205-17.

22. Kelbaek H, Terkelsen CJ, Helqvist S, et al. Randomized comparison of distal protection versus conventional treatment in primary percutaneous coronary intervention: the drug elution and dista protection in ST-elevation myocardial infarction (DEDICATION) trial. J Am Coll Cardiol 2008;51:899-905.

23. Task Force on the management of STseamiotESoC, Steg PG, James SK, Atar D, et al. ESC Guidelines for the management of acute myocardial infarction in patients presenting with ST-segment elevation. Eur Heart J 2012;33:2569-619.

24. Terkelsen CJ, Lassen JF, Norgaard BL, et al. Reduction of treatment delay in patients with ST-elevation myocardial infarction: impact of pre-hospital diagnosis and direct referral to primary percutanous coronary intervention. Eur Heart J 2005;26:770-7.

25. Van't Hof AW, Ten Berg J, Heestermans T, et al. Prehospital initiation of tirofiban in patients with ST-elevation myocardial infarction undergoing primary angioplasty (On-TIME 2): a multicentre, double-blind, randomised controlled trial. Lancet 2008;372:537-46.

26. Rakowski T, Siudak Z, Dziewierz A, et al. Early abciximab administration before transfer for primary percutaneous coronary interventions for ST-elevation myocardial infarction reduces 1-year mortality in patients with high-risk profile. Results from EUROTRANSFER registry. Am Heart $J$ 2009;158:569-75.

27. Petronio AS, De Carlo M, Strata E, et al. Impact of early abciximab administration on infarct size in patients with ST-elevation myocardial infarction. Int J Cardiol 2012;155:230-5.

28. Stone GW, Maehara A, Witzenbichler B, et al. Intracoronary abciximab and aspiration thrombectomy in patients with large anterior myocardial infarction: the INFUSE-AMI randomized trial. JAMA 2012;307:1817-26.

29. Wijnbergen I, Helmes $\mathrm{H}$, Tijssen J, et al. Comparison of drug-eluting and bare-metal stents for primary percutaneous coronary intervention with or without abciximab in ST-segment elevation myocardial infarction: DEBATER: the Eindhoven reperfusion study. JACC Cardiovasc Interv 2012;5:313-22.

30. Nielsen PH, Terkelsen CJ, Nielsen TT, et al. System delay and timing of intervention in acute myocardial infarction (from the Danish Acute Myocardial Infarction-2 [DANAMI-2] trial). Am J Cardiol 2011;108:776-81.

31. Luepker RV, Raczynski JM, Osganian S, et al. Effect of a community intervention on patient delay and emergency medical service use in acute coronary heart disease: the Rapid Early Action for Coronary Treatment (REACT) Trial. JAMA 2000;284:60-7. 